Aneurisma de vena esplénica

Aneurysm of the splenic vein

10.20960/angiologia.00303

03/09/2022 


\section{ICM 00303}

\section{Aneurisma de vena esplénica}

Aneurysm of the splenic vein

Silvia Maqueda Ara, Luis Ángel Suárez González, Cristina Nogal Arias, Carlos de la Infiesta García

Servicio de Angiología, Cirugía Vascular y Endovascular. Complejo Asistencial Universitario de León. León

Recibido: 23/03/2021

Aceptado: 25/04/2021

Correspondencia: Silvia Maqueda Ara. Servicio de Angiología, Cirugía Vascular y Endovascular. Complejo Asistencial Universitario de León. C/ Altos de Nava, s/n. Edificio Princesa Sofía, planta 11. 24001 León e-mail: s.maqueda.ara@gmail.com

DOI: $10.20960 /$ angiologia.00303

Conflicto de interés: los autores declaran no tener ningún conflicto de interés.

\section{CASO CLÍNICO}

Mujer de 79 años hipertensa y dislipémica, en seguimiento por quistes hepáticos. El control ecográfico objetiva dilatación de vena esplénica. Se solicita angioTC con identificación de aneurisma de vena esplénica de $3,7 \mathrm{~cm}$ de diámetro, próximo a unión de mesentérica superior-porta (Figs. 1 y 2 ).

\section{PREGUNTA}

¿Cuál de las siguientes afirmaciones sobre los aneurismas venosos esplénicos es falsa?: 
a) Son una rara anomalía.

b) Son más frecuentes en mujeres.

c) Su tratamiento es controvertido.

d) Tienen una evolución natural benigna, sin complicaciones potencialmente fatales.

\section{SOLUCIÓN}

Respuesta: d).

Tienen una evolución natural benigna, sin complicaciones potencialmente fatales.

\section{COMENTARIO}

Los aneurismas venosos esplénicos constituyen una entidad rara. EI primero fue descrito en 1953 por Lowenthal y Jacob y desde entonces, pese a un aumento de su incidencia, los casos descritos no alcanzan la centena (1-3). Su etiología parece multifactorial e incluye debilidad congénita de la pared del vaso y causas adquiridas (traumatismos, pancreatitis, hepatopatías, hipertensión portal, etc.) (1,2). La mayoría son hallazgos incidentales pero pueden producir dolor abdominal, náuseas, vómitos, y como complicación trombosis, ruptura con hemorragia intraperitoneal o gastrointestinal, obstrucción duodenal, compresión de estructuras adyacentes e hipertensión portal $(2,3)$. La evolución natural es desconocida, por eso su manejo resulta controvertido. Parece razonable intervenir los sintomáticos o complicados, considerar intervención profiláctica en pacientes de bajo riesgo con aneurismas $>3 \mathrm{~cm}$, y mantener actitud conservadora con seguimiento ecográfico/TC en los pequeños y pacientes de alto riesgo, sin existir consenso. En cuanto a cómo tratarlo, también hay debate, se puede con la modalidad endovascular transhepática o transesplénica y la cirugía abierta convencional; la localización y tamaño son imprescindibles para la toma de decisiones (2-4).

\section{BIBLIOGRAFÍA}


1. Cho SW, Marsh W, Fontes PA, Daily MF, Nalesnik M, Tublin M et al. Extrahepatic Portal Vein Aneurysm-Report of Six Patients and Review of the Literature. J Gastrointest Surg 2008;12(1):145-52. DOI: 10.1007/s11605-007-0313-x

2. Torres G, Hines GL, Monteleone F, Hon M, Diel J. Splenic vein aneurysm: Is it a surgical indication? J Vasc Surg 1999;29:71921.

3. Calsina L, Páramo M, Grochowicz L, Leal Jl, Bilbao Jl. Endovascular treatment of a splenic vein aneurysm through a transhepatic approach. Diagn Inter Radiol 2019; 25:166-8. DOI: 10.5152/dir.2019.18057

4. Heeren M, Op de Beek B, Van den Brande P. Aneurysm of the Splenic Vein. Acta Chir Belg 2004;104:322-4. DOI: 10.1080/00015458.2004.11679563

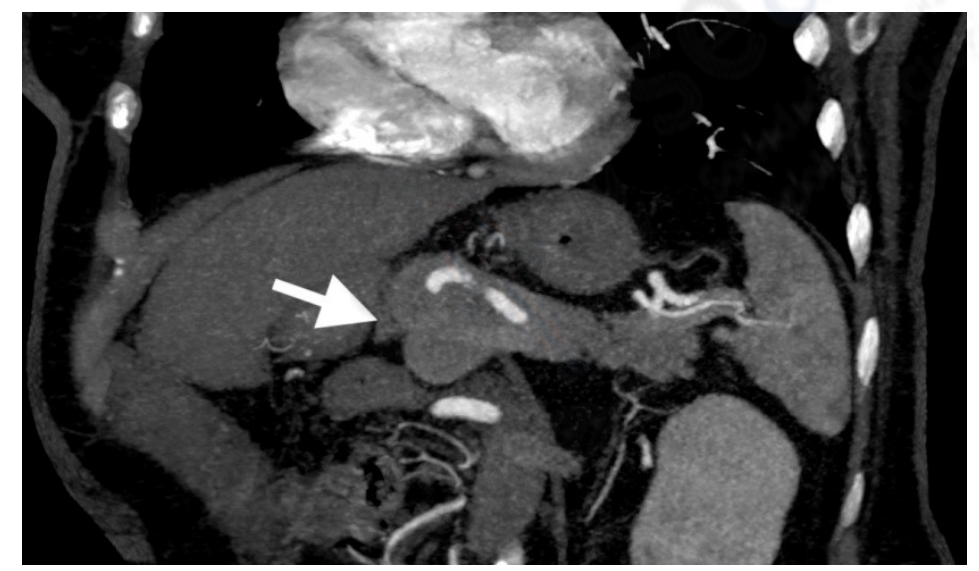

Figura 1. Aneurisma vena esplénica. Reconstrucción MIP de TC.

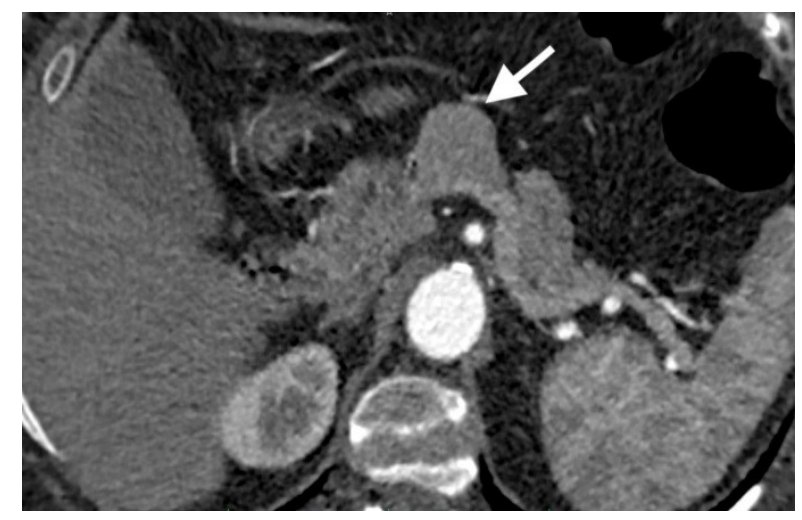

Figura 2. AngioTC. Aneurisma vena esplénica. 